\title{
The Licensing Factor Cdt1 Links Cell Cycle Progression to the DNA Damage Response
}

\author{
ALEXANDRA KANELLOU, NICKOLAOS NIKIFOROS GIAKOUMAKIS, \\ ANDREAS PANAGOPOULOS, SPYRIDON CHAMPERIS TSANIRAS and ZOI LYGEROU \\ School of Medicine, University of Patras, Patras, Greece
}

\begin{abstract}
The maintenance of genome integrity is essential for cellular survival and propagation. It relies upon the accurate and timely replication of the genetic material, as well as the rapid sensing and repairing of damage to DNA. Uncontrolled DNA replication and unresolved DNA lesions contribute to genomic instability and can lead to cancer. Chromatin licensing and DNA replication factor 1 (Cdt1) is essential for loading the minichromosome maintenance 2-7 helicase complex onto chromatin exclusively during the $G_{1}$ phase of the cell cycle, thus limiting DNA replication to once per cell cycle. Upon DNA damage, Cdt1 rapidly accumulates to sites of damage and is subsequently poly-ubiquitinated by the cullin 4-RING E3 ubiquitin ligase complex, in conjunction with the substrate recognition factor $\mathrm{Cdt} 2\left(\mathrm{CRL} 4^{\mathrm{Cdt} 2}\right)$, and targeted for degradation. We here discuss the cellular functions of Cdt1 and how it may interlink cell cycle regulation and DNA damage response pathways, contributing to genome stability.
\end{abstract}

During every cell division, cells must ensure that they pass down a full and accurate copy of their genetic material to their daughter cells. To achieve this, all eukaryotic cells carry out a strict series of events, known as the cell cycle, which permits genomic DNA to be copied once and only once during the $\mathrm{S}$ phase of the cell cycle, before one copy of each chromosome is passed down to the daughter cells during mitosis $(1,2)$. Multiple protein complexes associate with chromatin throughout the cell cycle to coordinate cell cycle events and ensure timely DNA replication and chromosome segregation

This article is freely accessible online.

Correspondence to: Zoi Lygerou, School of Medicine, University of Patras, 26504, Rio, Patras, Greece. Tel.: +30 2610 997610, Fax: +30 2610 997422, e-mail: lygerou@upatras.gr

Key Words: DNA replication, DNA repair, chromatin, cell cycle, genome stability, Cdt1, review.
$(1,2)$. In addition, mistakes made during DNA replication or damage to DNA brought about by endogenous or exogenous factors must be quickly sensed and repaired. For this reason, hundreds of cellular proteins constantly scan the DNA to recognize damaged sites and recruit additional protein complexes to orchestrate repair and signal to the cell cycle machinery the presence of damage and, therefore, the need to halt further cell cycle progression. This DNA damage response (DDR) must be closely coordinated with the cell cycle machinery to ensure the maintenance of genomic stability. Factors linking the DDR to the cell cycle have attracted significant attention in recent years (3-6), while defects in this coordination can lead to genomic instability and are closely linked to disease, most prominently to cancer $(7,8)$.

In this review, we focus on the chromatin licensing and DNA replication factor 1 (Cdt1), a cell cycle regulator essential for timely DNA replication. We discuss the cellular function of Cdt1, as well as its link with the pathways that sense and repair DNA damage. Moreover, we describe how this link could affect both cell cycle progression and cellular DNA damage response. Experimental data from our group (Figures 1-3) are used to illustrate key points, consistent with earlier findings.

\section{Cdt1 Is a Central Regulator of DNA Replication Licensing}

Cdt1 was originally identified in fission yeast as a gene regulated by the cell cycle transcription factor $\mathrm{Cdc10}$, and was named Cdc10-dependent transcript 1 (9). It was shown to be important both for entry into $\mathrm{S}$ phase and for arresting progression to mitosis in the absence of DNA replication (9). Functional characterization of Cdt 1 showed it to be required for the loading of minichromosome maintenance (MCM) proteins onto DNA during the $\mathrm{G}_{1}$ phase of the cell cycle in fission yeast (10) and Xenopus egg extracts (11). Cdt1 was also shown to enhance aberrant over-replication brought about by ectopic expression of the licensing factor Cdc18 in 
fission yeast (10-14). Subsequently, it was revealed that its function was conserved in all eukaryotes (15) and Cdt1 was accordingly renamed to chromatin licensing and DNA replication factor 1 .

In the normal cell cycle, DNA is licensed for a new round of DNA replication after passage through mitosis, through the association of the six-subunit MCM complex (MCM2-7) onto DNA replication origins $(16,17)$. Cdt1 and Cdc6 (Cdc18 in fission yeast) are essential for MCM loading, and therefore for DNA replication licensing. In mammalian cells, replication origins begin to be licensed in telophase, while the majority is licensed in late $G_{1}$, prior to $S$ phase onset (16, $18,19)$. The MCM complex is activated as a helicase when cells enter $\mathrm{S}$ phase, and moves ahead of the replication fork, unwinding DNA for replication. Origins that have already fired are not able to fire again within the same cell cycle, as licensing in inhibited and the MCM complex cannot load onto chromatin from $\mathrm{S}$ phase until completion of mitosis. Thus, restriction of MCM complex loading exclusively in the $\mathrm{G}_{1}$ phase is pivotal for the maintenance of genome integrity, and is ensured by the tight regulation of the loading factors Cdt 1 and Cdc6.

Cdt1 is tightly regulated so as to be present within the nucleus only during the $G_{1}$ phase of the cell cycle. In Figure 1 , it is shown that in cultured human breast cancer cells Cdt1 is detected only in cells that are in $G_{1}$, consistent with earlier work (20-22). This strict regulation of Cdt1 levels is evident in different tissues (23) and different species (15). Cdt1 protein levels are controlled through cell cycle-specific proteolysis. More specifically, following S phase entry, Cdt1 is poly-ubiquitinated and targeted for proteasome-dependent proteolysis by two major E3 ubiquitin ligases, a Skp1-CullinF-box protein complex containing $\mathrm{Skp} 2\left(\mathrm{SCF}^{\mathrm{Skp} 2}\right)$ and cullin ring ligase $\mathrm{CRL}^{\mathrm{Cdt} 2}(15,21)$. Aberrations in this control bring about untimely licensing and origin refiring within the same cell cycle (15). It has been demonstrated that Cdt 1 is misregulated in tumors (24-26), and this misregulation already occurs in early, precancerous lesions (27), while aberrant regulation of $\mathrm{Cdt} 1$ leads to dysplasia and malignancy in mice (28-30). Cdt1 is therefore believed to be an important contributor to genomic instability during tumor initiation and progression $(8,31,32)$.

\section{Cdt1 Is Proteolysed Following DNA Damage by the Cullin 4-RING E3 Ubiquitin Ligase CRL4 $4^{\text {dt2 }}$}

Cdt1 has been shown to link cell cycle regulation with the DNA damage response, as it is rapidly proteolyzed when cells experience damage in $\mathrm{G}_{1}$ (33), due to irradiation (33, 34), or drugs (35). As shown in Figure 2, Cdt1 levels drop when MCF-7 breast cancer cells are exposed to ultraviolet irradiation. This DNA damage-dependent proteolysis of Cdt1 is mediated by the CRL4 ${ }^{\mathrm{Cdt} 2}$ ubiquitin ligase $(21,36)$, which binds to proliferating cell nuclear antigen (PCNA) loaded onto damaged chromatin. Independent recruitment of Cdt1 and Cdt 2 onto DNA-bound PCNA was recently shown to be required for the recognition of $\mathrm{Cdt} 1$ by $\mathrm{CRL} 4{ }^{\mathrm{Cdt}} 2$, both after DNA damage and in S phase (37-39), ensuring that Cdt1 poly-ubiquitination takes place only on damaged or replicating DNA. Multiple DNA repair pathways bring about PCNA loading and Cdt1 proteolysis, including the xeroderma pigmentosum pathway and the mismatch repair pathway following UV-irradiation $(36,40,41)$, or the cellular response to double-strand breaks.

Cdt1 proteolysis following DNA damage has been suggested as a checkpoint, which inhibits entry into S phase, to ensure time for repair prior to the initiation of DNA replication. Indeed, Cdt1 depletion leads to decreased licensing, while mammalian cells have been shown to possess a checkpoint, which inhibits entry into $S$ phase with incomplete licensing (42-46). This checkpoint is dependent on p53 (44). However, in cancer cells as well as in cells entering the cell cycle from $\mathrm{G}_{0}(47,48)$, this checkpoint is dysfunctional contributing to the appearance of replication stress (8). Cdt1 proteolysis following DNA damage has also been suggested as a means to inhibit re-replication in damaged cells, where the checkpoints elicited as a response to the presence of damage culminate in the inhibition of cyclin-dependent kinases (CDKs), thus alleviating CDKmediated blocks to re-replication (49).

\section{Cdt1 Rapidly Accumulates at Sites of DNA Damage}

Cdt1 accumulates on damaged chromatin prior to its proteolysis. By using a pulsed laser to induce DNA damage at a specific subnuclear volume in living cells, Cdt1 was shown to be rapidly recruited to the site of DNA lesion, within minutes of the induction of damage (50). This is also evident when cells are locally irradiated with UV, through the use of micropore filters with defined pores $(37,51)$. As shown in Figure 3, following laser micro-irradiation of MCF7 breast cancer cells, Cdt1 accumulates at sites of damage, marked by the phosphorylated histone variant $\mathrm{H} 2 \mathrm{AX}(\gamma \mathrm{H} 2 \mathrm{AX})$.

PCNA and the PCNA interacting protein (PIP) box at the $\mathrm{N}$-terminus of $\mathrm{Cdt} 1$ are required for this recruitment, consistent with Cdt1 accumulation taking place through binding to chromatin loaded PCNA $(50,51)$. Using fluorescence recovery after photobleaching (FRAP) (52-54), Cdt1 was shown to exhibit dynamic binding to sites of damage $(37,50,55)$, in contrast to PCNA, which maintains stable interactions with damaged chromatin. The accumulation of Cdt1 to sites of damage is followed by its proteolysis, which is usually completed within $30 \mathrm{~min}$ to 2 $\mathrm{h}$, depending on the cell type $(37,50)$. Therefore, Cdt1 remains associated on damaged DNA for an appreciable time prior to its proteolysis. 

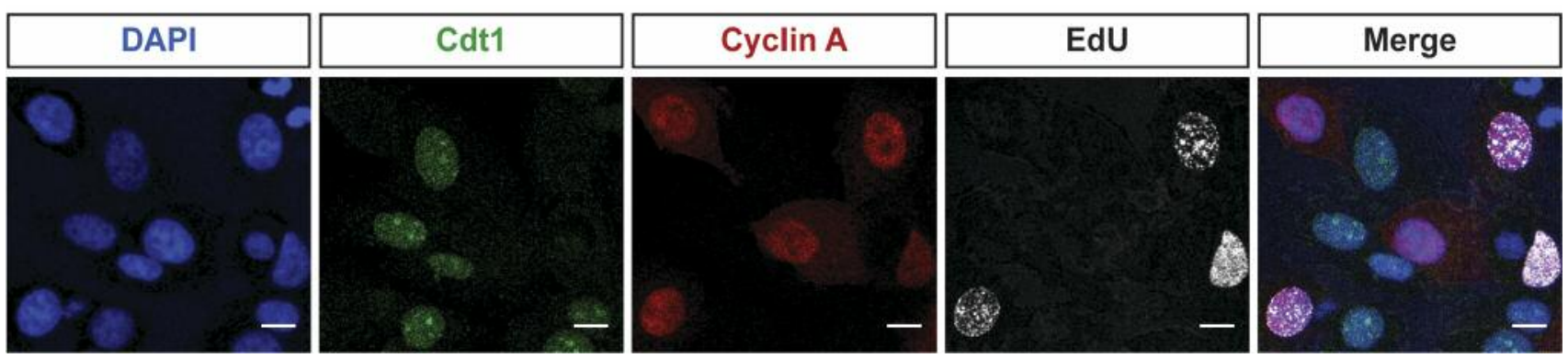

Figure 1. Cdt1 marks the $G_{1}$ phase of the cell cycle. MCF7 breast cancer cells were cultured and incubated with the thymidine analogue EdU, which is incorporated in the newly replicated DNA and marks cells in S-phase, for 10 min prior to fixation. Immunofluorescence was performed with specific antibodies against Cdt1 and Cyclin A, which is used as a marker of cells in $S$ and $G_{2}$ phases of the cell cycle. Cdt1 was detected specifically in the nuclei of cells which are negative for EdU and Cyclin A, and are therefore in the $G_{I}$ phase of the cell cycle. Nucleolar localization of Cdt1 is also evident. EdU was detected with the use of Click-iT ${ }^{T M}$ EdU Imaging kit (Invitrogen, Thermo Fischer Scientific). Nuclei were stained with DAPI. Images were obtained with a Leica SP5 Confocal microscope. Scale bar: $10 \mu \mathrm{m}$.

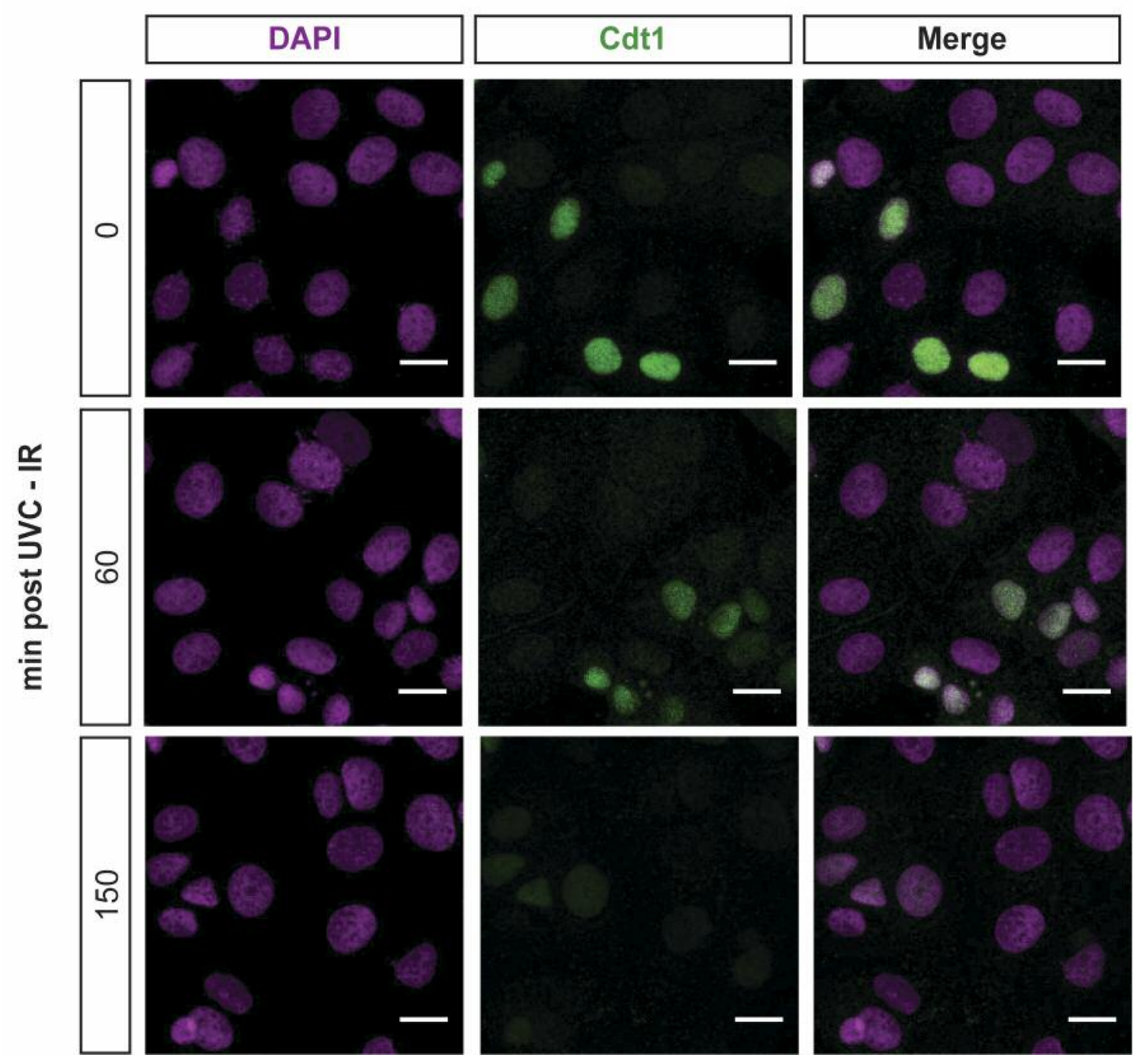

Figure 2. Cdt1 is degraded following ultraviolet (UV)-C irradiation. MCF7 breast cancer cells in culture were irradiated with a UV-C lamp at 10 $\mathrm{J} / \mathrm{m}^{2}$ and collected at 60 and $150 \mathrm{~min}$ following irradiation. The cells were fixed and immunofluorescence was performed with a specific antibody against Cdt1 and $\gamma H 2 A X$. Nuclei were stained with DAPI. Images were obtained with a Leica SP5 Confocal microscope. Scale bar: $10 \mu$ m. 

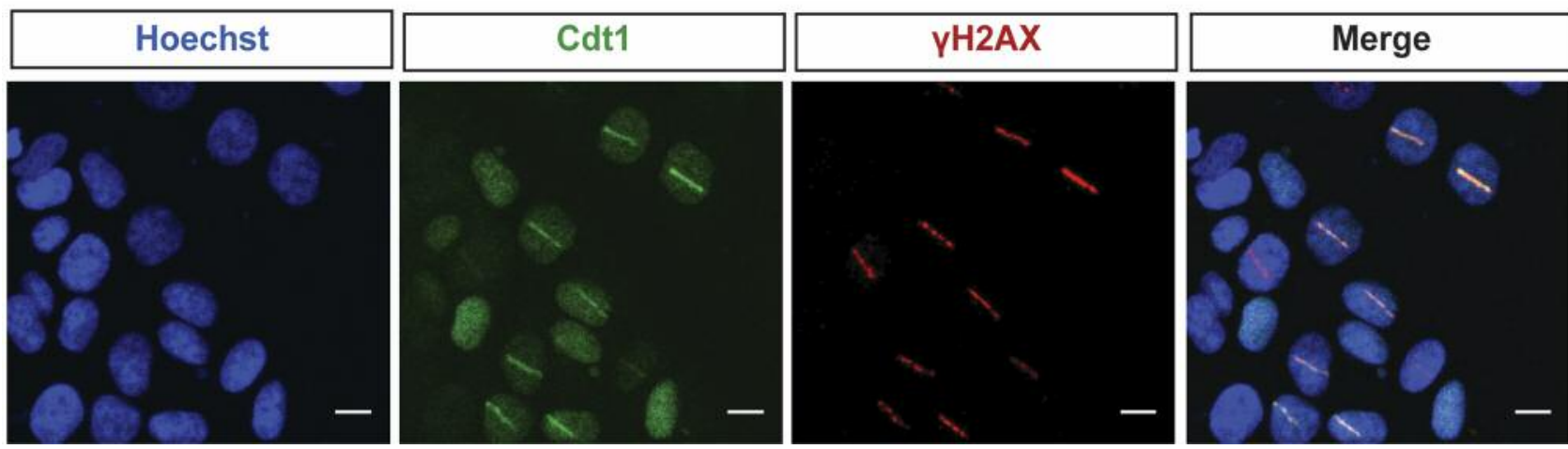

Figure 3. Cdt1 accumulates at sites of DNA damage. Laser micro-irradiation was performed in MCF7 breast cancer cells seeded in 35 mm imaging dishes ( $\mu$-Dish, ibidi, GmbH) with the use of ultraviolet (UV)-A pulsed laser (355 nm) mounted on an IX83 inverted Olympus microscope. The cells were fixed 10 min following irradiation and immunofluorescence was performed with a specific antibody against Cdt1 and $\gamma H 2 A X$. Nuclei were stained with Hoechst. Scale bar: $10 \mu \mathrm{m}$.

\section{Cdt1 Recruitment to Damaged DNA May Be Important for the DDR}

The rapid recruitment of Cdt1 to sites of DNA damage prior to its proteolysis brings about the question of the role of Cdt1 at sites of damage. The cell cycle-specific expression of Cdt1, together with its known properties and interactions, suggest different, non-mutually exclusive, scenarios.

Cdt1 is specifically expressed during the $G_{1}$ phase of the cell cycle, and its recruitment to sites of damage could signal to the cell the phase of the cell cycle to ensure selection of the appropriate repair pathway. Indeed, different repair pathways must be selected at different cell cycle phases, the most notable being the pathway to repair double-strand breaks. Double-strand breaks are preferentially repaired by nonhomologous-end-joining (NHEJ) during the $\mathrm{G}_{1}$ phase, when no sister chromatid is present (4). This pathway is however likely to introduce mutations and the alternative homologous recombination directed repair pathway (HDR) is the pathway of choice following entry into $\mathrm{S}$ phase, when a sister chromatid can direct error-free repair (4). Different factors have been shown to ensure the correct choice of double-strand break repair pathway during the cell cycle. Notably, a cyclindependent kinase (CDK)-mediated pathway employs the protein CtIP to enhance HDR when CDK levels are increased after the $G_{1}$ to $S$ phase transition (4). A second pathway was recently described, which uses a histone mark to promote homologous recombination only on newly synthesized chromatin. Specifically, histone $\mathrm{H} 4$ unmethylated at lysine 20 (H4K20me0), which marks post-replicative chromatin (56), is recognized by and recruits BRCA1/BARD1, thus directing homologous recombination only to replicated DNA (57). Similarly, the dimethylated H4K20me 2 on unreplicated DNA mediates the recruitment of the NHEJ pathway $(58,59)$. Of note, the methyltransferase that monomethylates H4K20, Set8, is also implicated in licensing (60). Set8 is recruited to sites of DNA damage and proteolyzed through the same pathway as Cdt1 $(39,61-63)$. Moreover, Set8 is required at sites of damage for the recruitment of the NHEJ factor 53BP1 (64, 65). It is intriguing to speculate that the presence of Cdt 1 at sites of damage could signal to the cell the phase of the cell cycle and/or could influence the recruitment and degradation of other CRL4 ${ }^{\text {Cdt2 }}$ targets, such as Set8.

A function for Cdt1 in fine-tuning recruitment of repair factors to damaged sites has been suggested for trans-lesion synthesis (TLS). Cdt1 recruitment to damaged DNA was shown to inhibit the accumulation of the TLS DNA polymerases eta (Pol $\eta$ ) and kappa (Pol к) (66). This is brought about by the efficient binding of the PIP degroncontaining Cdt1 to PCNA loaded on DNA, which competes with the binding of the PIP motif of polymerases eta and kappa. Thus, recruitment of Pol $\eta$ and Pol $\mathrm{k}$ to sites of damage, and therefore switch to the error-prone TLS, would only be possible following Cdt 1 proteolysis. It should be noted that the rate of CRL4 ${ }^{\mathrm{Cdt} 2}$-mediated Cdt1 proteolysis is regulated by multiple post-translational modifications, such as Cdt1 and Cdt2 phosphorylation $(15,39)$ as well as Cdt1 acetylation (67), providing a means of fine-tuning repair.

In addition, Cdt 1 recruitment could directly modify chromatin. Cdt1 directly interacts with HBO1, a histone acetylase (68) and the deacetylase HDAC11 (67). Furthermore, Cdt1 binds to Geminin (30) and recruits it onto chromatin (22), while Geminin has been shown to interact with multiple chromatin modifying and remodeling complexes $(69,70)$. It is conceivable that Cdt 1 recruitment to sites of damage could influence the chromatin state, in order to facilitate repair.

Cdt1 was recently shown to contain intrinsically disordered regions at its $\mathrm{N}$-terminus, which possess the ability to lead to liquid-liquid phase separation when mixed 
with DNA (71). The N-terminus of Cdt1 was previously shown to be required for chromatin association during the $\mathrm{G}_{1}$ phase in living cells (22). Liquid-liquid phase separation, which drives the formation of biomolecular condensates within cells, has attracted significant attention in recent years as a means of subcellular compartmentalization mediating various cellular processes (72). Both DNA replication and DNA repair are organized in supramolecular assemblies within the nucleus, called factories and foci respectively. 53BP1, a key upstream factor for NHEJ, was recently shown to exhibit phase separation properties during DNA repair (73, 74). It could be hypothesized that the physical properties of Cdt1 recruited to sites of damage may affect macromolecular assemblies on damaged chromatin through phase separation, a concept that merits further investigation.

\section{Conclusion}

Cdt1, a central cell cycle regulator, ensures that replication occurs once per cell cycle and links the cell cycle to DNA damage responses. This link is likely to affect cell cycle progression in the presence of damage, as Cdt1 degradation inhibits licensing and entry into $S$ phase in cells with an active licensing checkpoint. It may also affect DNA damage responses, by signaling the cell cycle phase, modifying chromatin or finetuning the recruitment of different factors to sites of DNA damage. Of note, Cdt1 over-activation directly leads to DNA damage through re-replication (75), while accurate licensing regulation is essential for avoiding replication stress and tumorigenesis (8). In addition to its role in DNA replication licensing and DNA damage responses, Cdt1 is also important for the correct execution of mitosis, being implicated in kinetochore attachment $(76,77)$, thereby linking DNA replication and repair to chromosome segregation. The observation that Cdt1 is often misregulated in cancer $(8,24-27$, $31,32,78)$ underscores the importance of understanding the Cdt1-mediated molecular pathways elicited in damaged cells.

\section{Conflicts of Interest}

The Authors declare that they have no conflicts of interest.

\section{Authors' Contributions}

All Authors contributed to writing and proofreading the manuscript. $\mathrm{AK}$ and NNG performed the experiments shown in figures (AK figure $1, \mathrm{NNG}$ figures 2 and 3 ) and prepared figures. AP surveyed the literature.

\section{Acknowledgements}

The Authors thank the Advanced Light Microscopy Facility of the University of Patras for assistance with microscopy and members of the Lygerou and Taraviras laboratories for fruitful discussions.

\section{Funding}

This project has been co-financed by the Operational Program "Human Resources Development, Education and Lifelong Learning" and is co-financed by the European Union (European Social Fund) and Greek national funds.

\section{References}

1 Vermeulen K, Van Bockstaele DR and Berneman ZN: The cell cycle: a review of regulation, deregulation and therapeutic targets in cancer. Cell Prolif 36(3): 131-149, 2003. PMID: 12814430. DOI: 10.1046/j.1365-2184.2003.00266.x

2 Blow JJ and Tanaka TU: The chromosome cycle: coordinating replication and segregation. Second in the cycles review series. EMBO Rep 6(11): 1028-1034, 2005. PMID: 16264427. DOI: 10.1038/sj.embor.7400557

3 Murray JM and Carr AM: Integrating DNA damage repair with the cell cycle. Curr Opin Cell Biol 52: 120-125, 2018. PMID: 29587168. DOI: 10.1016/j.ceb.2018.03.006

4 Hustedt $\mathrm{N}$ and Durocher D: The control of DNA repair by the cell cycle. Nat Cell Biol 19(1): 1-9, 2016. PMID: 28008184. DOI: $10.1038 / \mathrm{ncb} 3452$

5 Bartke $\mathrm{T}$ and Groth A: A chromatin-based signalling mechanism directs the switch from mutagenic to error-free repair of DNA double strand breaks. Mol Cell Oncol 6(4): 1605820, 2019. PMID: 31211233. DOI: 10.1080/2372 3556.2019 .1605820

6 Yekezare M, Gomez-Gonzalez B and Diffley JFX: Controlling DNA replication origins in response to DNA damage - inhibit globally, activate locally. J Cell Sci 126(6): 1297-1306, 2013. PMID: 23645160. DOI: 10.1242/jcs.096701

7 Jackson SP and Bartek J: The DNA-damage response in human biology and disease. Nature 461(7267): 1071-1078, 2009. PMID: 19847258. DOI: 10.1038/nature08467

8 Petropoulos M, Champeris Tsaniras S, Taraviras S and Lygerou $\mathrm{Z}$ : Replication licensing aberrations, replication stress, and genomic instability. Trends Biochem Sci 44(9): 752-764, 2019. PMID: 31054805. DOI: 10.1016/j.tibs.2019.03.011

9 Hofmann JF and Beach D: cdt1 is an essential target of the Cdc10/Sct1 transcription factor: requirement for DNA replication and inhibition of mitosis. EMBO J 13(2): 425-434, 1994. PMID: 8313888. DOI: 10.1002/j.1460-2075.1994.tb06277.x

10 Nishitani H, Lygerou Z, Nishimoto T and Nurse P: The Cdt1 protein is required to license DNA for replication in fission yeast. Nature 404(6778): 625-628, 2000. PMID: 10766248. DOI: $10.1038 / 35007110$

11 Maiorano D, Moreau J and Méchali M: XCDT1 is required for the assembly of pre-replicative complexes in Xenopus laevis. Nature 404(6778): 622-625, 2000. PMID: 10766247. DOI: $10.1038 / 35007104$

12 Yanow SK, Lygerou Z and Nurse P: Expression of Cdc18/Cdc6 and Cdt1 during G2 phase induces initiation of DNA replication. EMBO J 20(17): 4648-4656, 2001. PMID: 11532929. DOI: $10.1093 / \mathrm{emboj} / 20.17 .4648$

13 Gopalakrishnan V, Simancek P, Houchens C, Snaith HA, Frattini MG, Sazer S and Kelly TJ: Redundant control of rereplication in fission yeast. Proc Natl Acad Sci 98(23): 13114-13119, 2001. PMID: 11606752. DOI: 10.1073/pnas.221467598 
14 Lygerou Z and Nurse P: Controlling S-phase onset in fission yeast. Cold Spring Harb Symp Quant Biol 65: 323-332, 2000. PMID: 12760046 . DOI: $10.1101 / \mathrm{sqb} .2000 .65 .323$

15 Pozo PN and Cook JG: Regulation and function of Cdt1; A key factor in cell proliferation and genome stability. Genes (Basel) 8(1): 2, 2016. PMID: 28025526. DOI: 10.3390/genes 8010002

16 Symeonidou I-E, Taraviras S and Lygerou Z: Control over DNA replication in time and space. FEBS Lett 586(18): 2803-2812, 2012. PMID: 22841721. DOI: 10.1016/j.febslet.2012.07.042

17 Parker MW, Botchan MR and Berger JM: Mechanisms and regulation of DNA replication initiation in eukaryotes. Crit Rev Biochem Mol Biol 52(2): 107-144, 2017. PMID: 28094588. DOI: $10.1080 / 10409238.2016 .1274717$

18 Dimitrova DS, Prokhorova TA, Blow JJ, Todorov IT and Gilbert DM: Mammalian nuclei become licensed for DNA replication during late telophase. J Cell Sci 115(Pt 1): 51-59, 2002. PMID: 11801723 .

19 Kuipers MA, Stasevich TJ, Sasaki T, Wilson KA, Hazelwood KL, McNally JG, Davidson MW and Gilbert DM: Highly stable loading of $\mathrm{Mcm}$ proteins onto chromatin in living cells requires replication to unload. J Cell Biol 192(1): 29-41, 2011. PMID: 21220507. DOI: $10.1083 /$ jcb.201007111

20 Nishitani H, Taraviras S, Lygerou Z and Nishimoto T: The human licensing factor for DNA replication Cdt1 accumulates in G1 and is destabilized after initiation of S-phase. J Biol Chem 276(48): 44905-44911, 2001. PMID: 11555648. DOI: 10.1074/jbc.M105406200

21 Nishitani H, Sugimoto N, Roukos V, Nakanishi Y, Saijo M, Obuse C, Tsurimoto T, Nakayama KI, Nakayama K, Fujita M, Lygerou $\mathrm{Z}$ and Nishimoto T: Two E3 ubiquitin ligases, SCFSkp2 and DDB1-Cul4, target human Cdt1 for proteolysis. EMBO J 25(5): 1126-1136, 2006. PMID: 16482215. DOI: 10.1038/sj.emboj.7601002

22 Xouri G, Squire A, Dimaki M, Geverts B, Verveer PJ, Taraviras S, Nishitani H, Houtsmuller AB, Bastiaens PIH and Lygerou Z: Cdt 1 associates dynamically with chromatin throughout G1 and recruits Geminin onto chromatin. EMBO J 26(5): 1303-1314, 2007. PMID: 17318181. DOI: 10.1038/sj.emboj.7601597

23 Spella M, Britz O, Kotantaki P, Lygerou Z, Nishitani H, Ramsay RG, Flordellis C, Guillemot F, Mantamadiotis T and Taraviras S: Licensing regulators Geminin and Cdt1 identify progenitor cells of the mouse CNS in a specific phase of the cell cycle. Neuroscience 147(2): 373-387, 2007. PMID: 17533120. DOI: 10.1016/j.neuroscience.2007.03.050

24 Xouri G, Lygerou Z, Nishitani H, Pachnis V, Nurse P and Taraviras S: Cdt1 and geminin are down-regulated upon cell cycle exit and are over-expressed in cancer-derived cell lines. Eur J Biochem 271(16): 3368-3378, 2004. PMID: 15291814. DOI: $10.1111 / \mathrm{j} .1432-1033.2004 .04271 . x$

25 Karakaidos P, Taraviras S, Vassiliou L V., Zacharatos P, Kastrinakis NG, Kougiou D, Kouloukoussa M, Nishitani H, Papavassiliou AG, Lygerou Z and Gorgoulis VG: Overexpression of the replication licensing regulators hCdt 1 and hCdc6 characterizes a subset of non-small-cell lung carcinomas: synergistic effect with mutant p53 on tumor growth and chromosomal instability--evidence of E2F-1 transcriptional control over. Am J Pathol 165(4): 1351-1365, 2004. PMID: 15466399. DOI: $10.1016 /$ S0002-9440(10)63393-7

26 Bravou V, Nishitani H, Song SY, Taraviras S and Varakis J: Expression of the licensing factors, Cdt1 and Geminin, in human colon cancer. Int J Oncol 27(6): 1511-1518, 2005. PMID: 16273206. DOI: 10.3892/ijo.27.6.1511

27 Liontos M, Koutsami M, Sideridou M, Evangelou K, Kletsas D, Levy B, Kotsinas A, Nahum O, Zoumpourlis V, Kouloukoussa M, Lygerou Z, Taraviras S, Kittas C, Bartkova J, Papavassiliou AG, Bartek J, Halazonetis TD and Gorgoulis VG: Deregulated overexpression of hCdt1 and hCdc6 promotes malignant behavior. Cancer Res 67(22): 10899-10909, 2007. PMID: 18006835. DOI: 10.1158/0008-5472.CAN-07-2837

28 Seo J, Chung YS, Sharma GG, Moon E, Burack WR, Pandita TK and Choi K: Cdt1 transgenic mice develop lymphoblastic lymphoma in the absence of p53. Oncogene 24(55): 8176-8186, 2005. PMID: 16261166. DOI: 10.1038/sj.onc.1208881

29 Muñoz S, Búa S, Rodríguez-Acebes S, Megías D, Ortega S, de Martino A and Méndez J: In vivo DNA re-replication elicits lethal tissue dysplasias. Cell Rep 19(5): 928-938, 2017. PMID: 28467906. DOI: 10.1016/j.celrep.2017.04.032

30 Champeris Tsaniras S, Villiou M, Giannou AD, Nikou S, Petropoulos M, Pateras IS, Tserou P, Karousi F, Lalioti M-E, Gorgoulis VG, Patmanidi AL, Stathopoulos GT, Bravou V, Lygerou $\mathrm{Z}$ and Taraviras S: Geminin ablation in vivo enhances tumorigenesis through increased genomic instability. J Pathol 246(2): 134-140, 2018. PMID: 29952003. DOI: 10.1002/path.5128

31 Petropoulou C, Kotantaki P, Karamitros D and Taraviras S: Cdt1 and Geminin in cancer: markers or triggers of malignant transformation? Front Biosci 13(1): 4485-4494, 2008. PMID: 18508524. DOI: $10.2741 / 3018$

32 Champeris Tsaniras S, Kanellakis N, Symeonidou IE, Nikolopoulou P, Lygerou Z and Taraviras S: Licensing of DNA replication, cancer, pluripotency and differentiation: an interlinked world? Semin Cell Dev Biol 30: 174-180, 2014. PMID: 24641889. DOI: 10.1016/j.semcdb.2014.03.013

33 Higa LAA, Mihaylov IS, Banks DP, Zheng J and Zhang H: Radiation-mediated proteolysis of CDT1 by CUL4-ROC1 and CSN complexes constitutes a new checkpoint. Nat Cell Biol 5(11): 1008-1015, 2003. PMID: 14578910. DOI: 10.1038/ncb1061

$34 \mathrm{Hu}$ J, McCall CM, Ohta T and Xiong Y: Targeted ubiquitination of CDT1 by the DDB1-CUL4A-ROC1 ligase in response to DNA damage. Nat Cell Biol 6(10): 1003-1009, 2004. PMID: 15448697. DOI: $10.1038 /$ ncb1172

35 Stathopoulou A, Roukos V, Petropoulou C, Kotsantis P, Karantzelis N, Nishitani H, Lygerou Z and Taraviras S: Cdt1 is differentially targeted for degradation by anticancer chemotherapeutic drugs. PLoS One 7(3): e34621, 2012. PMID: 22479651. DOI: 10.1371/journal.pone.0034621

36 Shiomi Y, Hayashi A, Ishii T, Shinmyozu K, Nakayama J, Sugasawa $\mathrm{K}$ and Nishitani $\mathrm{H}$ : Two different replication factor $\mathrm{C}$ proteins, Ctf18 and RFC1, separately control PCNA-CRL4Cdt2mediated Cdt1 proteolysis during $\mathrm{S}$ phase and following UV irradiation. Mol Cell Biol 32(12): 2279-2288, 2012. PMID: 22493068. DOI: 10.1128/MCB.06506-11

37 Hayashi A, Giakoumakis NN, Heidebrecht T, Ishii T, Panagopoulos A, Caillat C, Takahara M, Hibbert RG, Suenaga N, Stadnik-Spiewak M, Takahashi T, Shiomi Y, Taraviras S, von Castelmur E, Lygerou Z, Perrakis A and Nishitani H: Direct binding of Cdt 2 to PCNA is important for targeting the CRL4Cdt2 E3 ligase activity to Cdt1. Life Sci alliance 1(6): e201800238, 2018. PMID: 30623174. DOI: 10.26508/lsa.201800238

38 Leng F, Saxena L, Hoang N, Zhang C, Lee L, Li W, Gong X, Lu $\mathrm{F}$, Sun $\mathrm{H}$ and Zhang $\mathrm{H}$ : Proliferating cell nuclear antigen interacts 
with the CRL4 ubiquitin ligase subunit CDT2 in DNA synthesisinduced degradation of CDT1. J Biol Chem 293(49): 1887918889, 2018. PMID: 30301766. DOI: 10.1074/jbc.RA118.003049

39 Panagopoulos A, Taraviras S, Nishitani $\mathrm{H}$ and Lygerou Z: CRL4Cdt2: Coupling genome stability to ubiquitination. Trends Cell Biol 30(4): 290-302, 2020. PMID: 32044173. DOI: 10.1016/j.tcb.2020.01.005

40 Tanaka M, Takahara M, Nukina K, Hayashi A, Sakai W, Sugasawa K, Shiomi Y and Nishitani H: Mismatch repair proteins recruited to ultraviolet light-damaged sites lead to degradation of licensing factor Cdt1 in the G1 phase. Cell Cycle 16(7): 673-684 2017. PMID: 28278049. DOI: 10.1080/15384101.2017.1295179

41 Panagopoulos A, Taraviras S and Lygerou Z: Mismatch repair regulates Cdt1 after UV damage. Cell Cycle 16(12): 1143-1144, 2017. PMID: 28426347. DOI: 10.1080/15384101.2017.1319687

42 Shreeram S, Sparks A, Lane DP and Blow JJ: Cell type-specific responses of human cells to inhibition of replication licensing. Oncogene 21(43): 6624-6632, 2002. PMID: 12242660. DOI: 10.1038/sj.onc.1205910

43 Feng D, Tu Z, Wu W and Liang C: Inhibiting the expression of DNA replication-initiation proteins induces apoptosis in human cancer cells. Cancer Res 63(21): 7356-7364, 2003. PMID: 14612534.

44 Nevis KR, Cordeiro-Stone M and Cook JG: Origin licensing and p53 status regulate Cdk2 activity during G1. Cell Cycle 8(12): 1952-1963, 2009. PMID: 19440053. DOI: $10.4161 / \mathrm{cc} .8 .12 .8811$

45 Limas JC and Cook JG: Preparation for DNA replication: the key to a successful S phase. FEBS Lett 593(20): 2853-2867, 2019. PMID: 31556113. DOI: 10.1002/1873-3468.13619

46 McIntosh D and Blow JJ: Dormant origins, the licensing checkpoint, and the response to replicative stresses. Cold Spring Harb Perspect Biol 4(10): a012955-a012955, 2012. PMID: 22904560. DOI: $10.1101 /$ cshperspect.a012955

47 Matson JP, House AM, Grant GD, Wu H, Perez J and Cook JG: Intrinsic checkpoint deficiency during cell cycle re-entry from quiescence. J Cell Biol 218(7): 2169-2184, 2019. PMID: 31186278. DOI: $10.1083 /$ jcb.201902143

48 Blow JJ: Defects in the origin licensing checkpoint stresses cells exiting G0. J Cell Biol 218(7): 2080-2081, 2019. PMID: 31266845. DOI: $10.1083 /$ jcb.201905181

49 Havens CG and Walter JC: Mechanism of CRL4(Cdt2), a PCNA-dependent E3 ubiquitin ligase. Genes Dev 25(15): 15681582, 2011. PMID: 21828267. DOI: 10.1101/gad.2068611

50 Roukos V, Kinkhabwala A, Colombelli J, Kotsantis P, Taraviras S, Nishitani H, Stelzer E, Bastiaens P and Lygerou Z: Dynamic recruitment of licensing factor Cdt1 to sites of DNA damage. J Cell Sci 124(Pt 3): 422-434, 2011. PMID: 21224399. DOI: 10.1242/jcs.074229

51 Ishii T, Shiomi Y, Takami T, Murakami Y, Ohnishi N and Nishitani H: Proliferating cell nuclear antigen-dependent rapid recruitment of Cdt1 and CRL4Cdt2 at DNA-damaged sites after UV irradiation in HeLa cells. J Biol Chem 285(53): 4199342000, 2010. PMID: 20929861. DOI: 10.1074/jbc.M110.161661

52 Rapsomaniki MA, Kotsantis P, Symeonidou I-E, Giakoumakis N-N, Taraviras S and Lygerou Z: easyFRAP: an interactive, easy-to-use tool for qualitative and quantitative analysis of FRAP data. Bioinformatics 28(13): 1800-1801, 2012. PMID: 22543368. DOI: 10.1093/bioinformatics/bts241

53 Giakoumakis NN, Rapsomaniki MA and Lygerou Z: Analysis of protein kinetics using fluorescence recovery after photobleaching
(FRAP). Methods Mol Biol 1563: 243-267, 2017. PMID: 28324613. DOI: 10.1007/978-1-4939-6810-7_16

54 Koulouras G, Panagopoulos A, Rapsomaniki MA, Giakoumakis NN, Taraviras S and Lygerou Z: EasyFRAP-web: a web-based tool for the analysis of fluorescence recovery after photobleaching data. Nucleic Acids Res 46(W1): W467-W472, 2018. PMID: 29901776. DOI: 10.1093/nar/gky508

55 Rapsomaniki MA, Cinquemani E, Giakoumakis NN, Kotsantis P, Lygeros $\mathrm{J}$ and Lygerou Z: Inference of protein kinetics by stochastic modeling and simulation of fluorescence recovery after photobleaching experiments. Bioinformatics 31(3): 355-362, 2015. PMID: 25273108. DOI: 10.1093/bioinformatics/btu619

56 Saredi G, Huang H, Hammond CM, Alabert C, Bekker-Jensen S, Forne I, Reverón-Gómez N, Foster BM, Mlejnkova L, Bartke T, Cejka P, Mailand N, Imhof A, Patel DJ and Groth A: H4K20me0 marks post-replicative chromatin and recruits the TONSL-MMS22L DNA repair complex. Nature 534(7609): 714718, 2016. PMID: 27338793. DOI: 10.1038/nature18312

57 Nakamura K, Saredi G, Becker JR, Foster BM, Nguyen N V., Beyer TE, Cesa LC, Faull PA, Lukauskas S, Frimurer T, Chapman JR, Bartke T and Groth A: H4K20me0 recognition by BRCA1-BARD1 directs homologous recombination to sister chromatids. Nat Cell Biol 21(3): 311-318, 2019. PMID: 30804502. DOI: 10.1038/s41556-019-0282-9

58 Pellegrino S, Michelena J, Teloni F, Imhof R and Altmeyer M: Replication-coupled dilution of H4K20me2 guides 53BP1 to pre-replicative chromatin. Cell Rep 19(9): 1819-1831, 2017. PMID: 28564601. DOI: 10.1016/j.celrep.2017.05.016

59 Simonetta M, de Krijger I, Serrat J, Moatti N, Fortunato D, Hoekman L, Bleijerveld OB, Altelaar AFM and Jacobs JJL: H4K20me2 distinguishes pre-replicative from post-replicative chromatin to appropriately direct DNA repair pathway choice by 53BP1-RIF1-MAD2L2. Cell Cycle 17(1): 124-136, 2018. PMID: 29160738. DOI: 10.1080/15384101.2017.1404210

60 Tardat M, Brustel J, Kirsh O, Lefevbre C, Callanan M, Sardet C and Julien E: The histone H4 Lys 20 methyltransferase PR-Set7 regulates replication origins in mammalian cells. Nat Cell Biol 12(11): 1086-1093, 2010. PMID: 20953199. DOI: 10.1038/ ncb2113

61 Jørgensen S, Eskildsen M, Fugger K, Hansen L, Larsen MSY, Kousholt AN, Syljuåsen RG, Trelle MB, Jensen ON, Helin K and Sørensen CS: SET8 is degraded via PCNA-coupled CRL4(CDT2) ubiquitylation in S phase and after UV irradiation. J Cell Biol 192(1): 43-54, 2011. PMID: 21220508. DOI: $10.1083 /$ jcb.201009076

62 Oda H, Hübner MR, Beck DB, Vermeulen M, Hurwitz J, Spector DL and Reinberg D: Regulation of the histone H4 monomethylase PR-Set7 by CRL4(Cdt2)-mediated PCNA-dependent degradation during DNA damage. Mol Cell 40(3): 364-376, 2010. PMID: 21035370. DOI: $10.1016 /$ j.molcel.2010.10.011

63 Centore RC, Havens CG, Manning AL, Li J-M, Flynn RL, Tse A, Jin J, Dyson NJ, Walter JC and Zou L: CRL4(Cdt2)mediated destruction of the histone methyltransferase Set8 prevents premature chromatin compaction in S phase. Mol Cell 40(1): 22-33, 2010. PMID: 20932472. DOI: 10.1016/j.molcel. 2010.09.015

64 Dulev S, Tkach J, Lin S and Batada NN: SET8 methyltransferase activity during the DNA double-strand break response is required for recruitment of 53BP1. EMBO Rep 15(11): 1163-1174, 2014. PMID: 25252681. DOI: 10.15252/embr.201439434 
65 Tuzon CT, Spektor T, Kong X, Congdon LM, Wu S, Schotta G, Yokomori K and Rice JC: Concerted activities of distinct H4K20 methyltransferases at DNA double-strand breaks regulate 53BP1 nucleation and NHEJ-directed repair. Cell Rep 8(2): 430-438, 2014. PMID: 25001286. DOI: 10.1016/j.celrep.2014.06.013

66 Tsanov N, Kermi C, Coulombe P, Van der Laan S, Hodroj D and Maiorano D: PIP degron proteins, substrates of CRL4Cdt2, and not PIP boxes, interfere with DNA polymerase $\eta$ and $\mathrm{K}$ focus formation on UV damage. Nucleic Acids Res 42(6): 3692-3706, 2014. PMID: 24423875. DOI: $10.1093 / \mathrm{nar} / \mathrm{gkt} 1400$

67 Glozak MA and Seto E: Acetylation/deacetylation modulates the stability of DNA replication licensing factor Cdt1. J Biol Chem 284(17): 11446-11453, 2009. PMID: 19276081. DOI: 10.1074/jbc.M809394200

68 Miotto B and Struhl K: HBO1 histone acetylase is a coactivator of the replication licensing factor Cdt1. Genes Dev 22(19): 2633-2638, 2008. PMID: 18832067. DOI: 10.1101/gad.1674108

69 Patmanidi AL, Champeris Tsaniras S, Karamitros D, Kyrousi C, Lygerou $\mathrm{Z}$ and Taraviras S: Concise review: Geminin-A tale of two tails: DNA replication and transcriptional/epigenetic regulation in stem cells. Stem Cells 35(2): 299-310, 2017. PMID: 27859962. DOI: $10.1002 /$ stem.2529

70 Champeris Tsaniras S, Delinasios GJ, Petropoulos M, Panagopoulos A, Anagnostopoulos AK, Villiou M, Vlachakis D, Bravou V, Stathopoulos GT and Taraviras S: DNA Replication inhibitor geminin and retinoic acid signaling participate in complex interactions associated with pluripotency. Cancer Genomics Proteomics 16(6): 593-601, 2019. PMID: 31659113. DOI: $10.21873 / \operatorname{cgp} .20162$

71 Parker MW, Bell M, Mir M, Kao JA, Darzacq X, Botchan MR and Berger JM: A new class of disordered elements controls DNA replication through initiator self-assembly. Elife 8: 1-35, 2019. PMID: 31560342. DOI: 10.7554/eLife.48562

72 Boeynaems S, Alberti S, Fawzi NL, Mittag T, Polymenidou M, Rousseau F, Schymkowitz J, Shorter J, Wolozin B, Van Den Bosch L, Tompa P and Fuxreiter M: Protein phase separation: A new phase in cell biology. Trends Cell Biol 28(6): 420-435, 2018. PMID: 29602697. DOI: 10.1016/j.tcb.2018.02.004
73 Kilic S, Lezaja A, Gatti M, Bianco E, Michelena J, Imhof R and Altmeyer M: Phase separation of 53BP1 determines liquid-like behavior of DNA repair compartments. EMBO J 38(16): e101379, 2019. PMID: 31267591. DOI: 10.15252/embj.2018101379

74 Piccinno R, Minneker V and Roukos V: 53BP1-DNA repair enters a new liquid phase. EMBO J 38(16): 1-3, 2019. PMID: 31355472. DOI: $10.15252 / \mathrm{embj} .2019102871$

75 Vaziri C, Saxena S, Jeon Y, Lee C, Murata K, Machida Y, Wagle N, Hwang DS and Dutta A: A p53-dependent checkpoint pathway prevents rereplication. Mol Cell 11(4): 997-1008, 2003. PMID: 12718885. DOI: 10.1016/S1097-2765(03)00099-6

76 Varma D, Chandrasekaran S, Sundin LJR, Reidy KT, Wan X, Chasse DAD, Nevis KR, DeLuca JG, Salmon ED and Cook JG: Recruitment of the human Cdt1 replication licensing protein by the loop domain of $\mathrm{Hec} 1$ is required for stable kinetochoremicrotubule attachment. Nat Cell Biol 14(6): 593-603, 2012. PMID: 22581055. DOI: $10.1038 / \mathrm{ncb} 2489$

77 Agarwal S, Smith KP, Zhou Y, Suzuki A, McKenney RJ and Varma D: Cdt1 stabilizes kinetochore-microtubule attachments via an Aurora B kinase-dependent mechanism. J Cell Biol 217(10): 3446-3463, 2018. PMID: 30154187. DOI: 10.1083/jcb.201705127

78 Petrakis TG, Komseli E-S, Papaioannou M, Vougas K, Polyzos A, Myrianthopoulos V, Mikros E, Trougakos IP, Thanos D, Branzei D, Townsend $\mathrm{P}$ and Gorgoulis VG: Exploring and exploiting the systemic effects of deregulated replication licensing. Semin Cancer Biol 37-38: 3-15, 2016. PMID: 26707000. DOI: 10.1016/j.semcancer.2015.12.002
Received March 1, 2020 Revised April 6, 2020 Accepted April 14, 2020 